\title{
Problems of protection against virus B hepatitis
}

\author{
Sheila PolakofF \\ M.D., M.F.C.M., D.P.H. \\ Epidemiological Research Laboratory, Central Public Health Laboratory, Colindale Avenue, \\ London NW9
}

\begin{abstract}
Summary
Various methods have been employed to reduce hepatitis $B$ infections among patients and staff at high risk. Routine screening tests of all blood donors for hepatitis B surface antigen has reduced post-transfusion hepatitis B. After a control and prevention programme was instituted hepatitis B cross-infection was eliminated from haemodialysis units in Britain. Prophylaxis with specific immunoglobulin reduced attack rates of clinical hepatitis $B$, after accidental inoculation with infective material, to about $2 \%$. Endemic hepatitis B in hospitals for the mentally subnormal remains a problem.
\end{abstract}

\section{Protection against virus B hepatitis}

It is well known that the anxiety aroused by a communicable disease in any population is related not so much to its incidence as to its severity, in particular, to the risk of an attack leading to serious incapacity or death. There can be no doubt that reports of outbreaks of hepatitis in some hospital departments and the deaths of some infected staff, although small in number, has given rise among hospital staff in general to fear of acquiring hepatitis $B$ virus (HBV) infection in the course of work. In turn, this has led to the recognition of hepatitis B as an occupational hazard and to its inclusion in the group of prescribed diseases (Social Security Act, 1975). However, before considering ways and means of preventing staff and patients from acquiring HBV infections, an attempt to assess the size of the risk should be made.

\section{Prevalence of hepatitis $B$}

In the U.K., hepatitis caused by virus A, B or other agents is a disease of relatively low incidence as measured by notifications of infective jaundice. In England in 1973, there were less than 8,000 notifications, a rate of sixteen per 100,000 population, and the rate has remained at a similar level in $\mathbf{1 9 7 4}$ and, so far, in 1975. The total number of deaths from infectious hepatitis in 1973 was 121 . There is no means of knowing how many of the notified cases or deaths were caused by HBV infections, but it is accepted that virus $\mathrm{A}$ is a more common cause of hepatitis than virus $B$.

Hepatitis $B$ surface antigen $\left(\mathrm{HB}_{\mathrm{s}} \mathrm{Ag}\right)$, produced during active replication of $\mathrm{HBV}$, is a marker of infection. The $\mathrm{HB}_{\mathrm{S}} \mathrm{Ag}$ carrier rate in the general population is a good indicator of the prevalence of hepatitis B in any country. In England, this rate has been estimated at approximately $0 \cdot 1 \%$ (Maycock, 1972) _ one of the lowest rates in the world.

Since mid-1972, an approximate estimate of the incidence of hepatitis B in the U.K. has been provided by reports of acute hepatitis $B$ infections, confirmed by laboratory tests, from most laboratories 0 in the U.K. to the Epidemiological Research Labora- 8 tory of the Public Health Laboratory Service. The annual total of reports has increased over 3 years, but this probably reflects physicians' increasing? awareness of the fact that any attack of hepatitis may be caused by HBV and the availability and increasing sensitivity of laboratory tests for hepatitis $B$ rather than a real increase in incidence. During the 3 years of reporting, $6-7 \%$ of the reports were of infections of health service staff (Table 1)-a total of 156 cases. The cases according to staff category were as follows: medical 44; nursing 64; laboratory 24 ; ancillary 17 ; dentists 7 .

It seems that, although hepatitis B is an occupational hazard to health service staff, the risk has been small during the past 3 years in the U.K. It is likely that the hazard to staff has been reduced by various measures that have been taken. These vary according to the area in which staff work or according to the treatment of the patients, and therefore they will be described at the same time as the various groups of patients and staff at risk are considered.

Patients and staff at high risk of hepatitis B infection

(1) Patients transfused with blood or its products. In the U.K. before $\mathrm{HB}_{\mathrm{s}} \mathrm{Ag}$ screening of all blood donors was undertaken by the Blood Transfusion Service, the chance of a unit of blood containing HBV was approximately $1 / 1000$. The methods employed for $\mathrm{HB}_{\mathrm{s}} \mathrm{Ag}$ testing have become increasingly sensitive and they seem successful in 
TABLE 1. Laboratory-confirmed results of acute hepatitis B made to the Epidemiological Research Laboratory PHLS July 1972-June 1975.

\begin{tabular}{cccc}
\hline & \multicolumn{2}{c}{$\begin{array}{c}\text { Cases of laboratory-confirmed acute } \\
\text { hepatitis B }\end{array}$} \\
\cline { 2 - 4 } & & \multicolumn{2}{c}{ Health care staff } \\
\cline { 2 - 4 } Period & Total & No. & $\%$ \\
\hline July 1972-June 1973 & 681 & 46 & $6 \cdot 8$ \\
July 1973-June 1974 & 779 & 52 & $6 \cdot 8$ \\
July 1974-June 1975 & $927^{*}$ & $58^{*}$ & $6 \cdot 3$ \\
\hline
\end{tabular}

* Provisional estimate.

reducing post-transfusion hepatitis $\mathbf{B}$ although viruses other than HBV may cause long incubation post-transfusion hepatitis (Alter et al., 1975).

(2) Patients and staff of haemodialysis units. The outbreaks of hepatitis B that have arisen in the past are so well known that they require no further description. Indeed, it was the infections and deaths among staff in some of these units that initiated the alarm about hospital-acquired hepatitis B. When $\mathrm{HB}_{\mathrm{s}} \mathrm{Ag}$ tests became available it was shown that patients with chronic renal failure tend to respond to $\mathrm{HBV}$ by becoming persistent asymptomatic carriers of the infection, probably because of some abnormality of immune response. Cross-infection between patients in the units leads to a proliferation of carriers who form a reservoir for further cross infection of patients and staff. A control and prevention programme (Polakoff, 1971; Polakoff, Cossart and Tillett, 1972; Advisory Group Report, 1972), based on $\mathrm{HB}_{\mathrm{s}} \mathrm{Ag}$ tests before admission, further tests at regular intervals, dialysis in isolation of $\mathrm{HB}_{\mathrm{s}} \mathrm{Ag}$ carriers and careful cross-infection precautions has been in operation for 6 years. The incidence of HBV infection reached a peak in 1970 and declined steadily afterwards (Fig. 1). The last outbreak was brought under control in 1973 (Public Health Laboratory Service Report, 1974) and there have been no outbreaks since. Approximately $75 \%$ of the units in the U.K. are included in an ongoing survey. Over the years in which the control and prevention programme has been maintained in the U.K., evidence has emerged of increasing crossinfection in haemodialysis units in other countries. Szmuness et al. (1974a) showed that, in fifteen of these units in the U.S.A. in $1973,16.8 \%$ of the patients and $2.4 \%$ of the staff were $\mathrm{HB}_{\mathrm{s}} \mathrm{Ag}$ carriers. The position in Europe as a whole was no better, e.g. in 1972 in 587 units $19.6 \%$ of the patients were $\mathrm{HB}_{\mathrm{s}} \mathrm{Ag}$ carriers; 499 members of staff contracted hepatitis and twelve $(2 \cdot 4 \%)$ died (Gurland et al., 1973). The position in Europe in 1973 was little changed (Parsons, 1975). There can be little doubt that the control and prevention programme protected patients

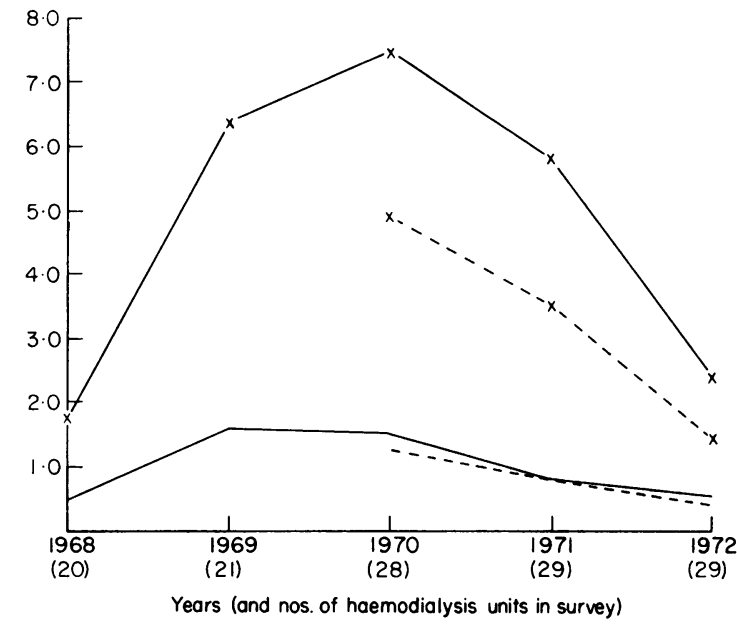

FIG. 1. Attack rates $(\%)$ of all hepatitis among patients and staff in haemodialysis units during years 1968-1972 and attack rates of $\mathrm{HB}_{\mathrm{s}} \mathrm{Ag}$ associated hepatitis during years 1970-1972. Total hepatitis attack rate: patients, $\times-\times-\times$; staff, $\longrightarrow . \mathrm{HB}_{\mathbf{s}} \mathrm{Ag}$ associated hepatitis attack rate: patients, $\times \cdots \times$; staff, $\cdots$.

and staff in British units from similar rates of infection.

(3) Hospitals for the mentally subnormal. HBV infection is common in these institutions (Sutnick et al., 1968). Abnormalities of immune response, inherent in some patients (e.g. mongols) and druginduced in others, tend to cause persistent asymptomatic carriage after infection with HBV. The infection becomes endemic with a large number of carriers and occasional acute attacks among patients or staff.

In Britain nothing has yet been done to control this problem, probably because a programme similar to that devised for haemodialysis units would be difficult to organize among these patients and in their environment. Studies in the U.S.A. (Szmuness et al., 1974b) suggest that IG containing small amounts of antibody to $\mathrm{HB}_{\mathrm{s}} \mathrm{Ag}$ may prevent antigenaemia in these patients but further data are required for confirmation.

(4) All health service staff. There can be no doubt that HBV infection can be transmitted to staff who accidentally inoculate themselves with, or ingest, the blood of either $\mathrm{HB}_{\mathrm{s}} \mathrm{Ag}$ carrier patients or cases of hepatitis $B$. The role of other body fluids in transmission is less clear. $\mathbf{H B}_{\mathrm{s}} \mathbf{A g}$ has been detected in high titres in ascitic fluid of antigenaemic patients and it is likely that such fluid is infective. Some workers, using sensitive techniques, have detected $\mathrm{HB}_{\mathrm{s}} \mathrm{Ag}$ in small amounts in some samples of saliva of patients with antigenaemia (Villarejos et al., 1974). 
It is less likely that urine and faeces contain HBV but any body fluid may contain extravasated serum. It follows therefore that staff should take reasonable precautions at all times to avoid accidents with blood or any body fluids whether or not they are known to contain $\mathrm{HB}_{s} \mathrm{Ag}$. When such accidents occur they should be reported promptly to the appropriate physician so that $\mathrm{HB}_{\mathrm{S}} \mathrm{Ag}$ tests can be made. If $\mathbf{H B}_{\mathrm{s}} \mathrm{Ag}$ is found in the serum or other body fluid of the relevant patient, prophylaxis is available for the person who sustained the accident.

Anti-HB immunoglobulin (anti-HBs $I G)$ in the prophylaxis of hepatitis $B$

British human normal immunoglobulin contains little or no detectable anti-HB $\mathrm{HB}_{\mathrm{s}}$ and therefore it cannot be expected to protect against HBV. Immunoglobulin with high titres of anti-HB $\mathrm{H}_{\mathrm{s}}$ can be obtained either by plasmaphoresis of volunteers or by collection of plasma pools from suitable routine blood donors.

British anti-HB IG $_{\mathbf{s}}$ is prepared at the Lister Institute from plasma pools by a modified Cohn fractionation technique. A Medical Research Council Study was begun in September 1973 to determine the incidence of HBV infection among persons who sustained one of the following accidents: penetration of the skin, contamination of the conjunctiva or of cuts or abrasions of the skin with, or ingestion of, material containing $\mathrm{HB}_{\mathrm{s}} \mathrm{Ag}$ and who were given $500 \mathrm{mg}$ anti-HB $\mathrm{IG}$ i.m. within approximately 14 days of the accident. A control group was not included.

A preliminary report of this study has been made (Polakoff and Maycock, 1975). A full analysis of the results of the 2-year study is not yet available but further results show a $2 \%$ attack rate among 176 participants followed-up for 6 months or more (Table 2).

TABLE 2. Preliminary results of MRC trial of anti-HB ${ }_{s}{ }^{*}$ immunoglobulin

Trial participants with follow-up $\geqslant 6$ months

\begin{tabular}{|c|c|c|c|}
\hline \multirow[b]{2}{*}{ Total No. } & \multicolumn{2}{|c|}{$\begin{array}{l}\text { With clinical } \\
\text { hepatitis B }\end{array}$} & \multirow{2}{*}{$\begin{array}{c}\text { With persistent } \\
\text { HB }_{\text {sg but no }} \\
\text { clinical hepatitis } \\
\text { No. }\end{array}$} \\
\hline & No & $\%$ & \\
\hline $176^{*}$ & 4 & $2 \cdot 3$ & 0 \\
\hline
\end{tabular}

* Two hundred and thirteen participants, but thirty-seven $(17 \%)$ lost to follow-up.

The onset of illness in the four participants who developed clinical hepatitis with $\mathrm{HB}_{\mathrm{s}} \mathrm{Ag}$ was 17,20 , 21 and 23 weeks after the accident; none of the attacks was severe and all but one cleared $\mathrm{HB}_{\mathrm{s}} \mathrm{Ag}$ from the serum within a few weeks of onset. None of the participants developed persistent asymptomatic antigenaemia. Only eight participants reported adverse reactions to the immunoglobulin; all were minor and transient.

The protective effect of anti-HB IG cannot be assessed by the results of this study because there was no control group, but two controlled trials in the U.S.A. show a protective effect of high titre antiHB $_{\mathrm{s}}$ IG (Seeff et al., 1975; Grady and Lee, 1975). Nevertheless, the material is not completely protective. All three studies indicate that clinical hepatitis B can be expected to develop in $1-2 \%$ of those who receive prophylaxis after accidental exposure.

Controlled trials of the material in haemodialysis unit patients and staff in the U.S.A. also showed a protective effect but again it was incomplete (Prince et al., 1975); the use of anti-HB $\mathrm{HG}_{\mathrm{s}} \mathrm{I}$ in haemodialysis units is unlikely completely to eliminate HBV crossinfection from the units.

\section{References}

ADVISORY Group REPORT (1972) Hepatitis and the treatment of chronic renal failure 1970-1972. Department of Health and Social Security, Scottish Home and Health Department Welsh Office.

Alter, H.J., Purcell, R.H., Holland, P.V., FeinstoneS.M., Morrow, A.G. \& Moritsugu, Y. (1975) Clinical and serological analysis of transfusion-associated hepatitis Lancet, ii, 838.

GraDY, G.F. \& LEE, V.A. (1975) Hepatitis B immune globulin-prevention of hepatitis from accidental exposure among medical personnel. New England Journal of Medicine, 293, 1067.

Gurland, H.J., Brunner, F.P., v. Dehn, H., Harlen, H., PARSONS, F.M. \& SCHÄRER, K. (1973) In: Proceedings of the European Dialysis and Transplantation Association (Ed. by J. F. Moorhead, R. R. Baillod and C. Mion, Vol. 10, p. 156. Pitman Medical, London.

MAYCOCK, W. D'A. (1972) Hepatitis in transfusion services. British Medicol Bulletin, 28, 163.

Parsons, F.M. (1975) Personal communication.

Polakoff, S. (1971) The prevention of hepatitis in haemodialysis units. Postgraduate Medical Journal, 47, 501.

Polakoff, S., Cossart, Y.E. \& Tillett, H.E. (1972) Hepatitis in dialysis units in the United Kingdom. British Medical Journal, 3, 94.

Polakoff, S. \& Maycock, W. D'A. (1975) Anti-HB Ag immunoglobulin after inoculation injuries. In: Developments in Biological Standardization, Vol. 30, p. 329. S. Karger, Basel.

Prince, A.M., Szmuness, W., Mann, M.K., Vyas, G.N., Grady, G.F., ShaPIro, F.L., Suki, W.N., Friedman, E.A. \& Stenzel, K.H. (1975) Hepatitis B 'immune' globulin: effectiveness in prevention of dialysis-associated hepatitis. New England Journal of Medicine, 293, 1060.

Public Health Laboratory Service Report (1974) Decrease in the incidence of hepatitis in dialysis units associated with prevention programme. British Medical Journal, 4, 751.

SeefF, L.B., Zimmerman, H.J., Wright, E.C., FelSher, B.F., Finkelstein, J.D., Garcia-Pont, P., GreenleE, H.B., Dietz, A.A., Hamilton, J., Koff, R.S., Leevy, C.M., Kiernan, T., Tamburro, C.H., Schiff, E.R., VlahCEVIC, 
Z., Zemel, R., Zimmon, D.S. \& NATH, N. (1975) Efficacy of hepatitis B immune serum globulin after accidental exposure: preliminary report of the Veterans Administration Cooperative Study. Lancet, ii, 939.

Social Security Act (1975) Viral hepititis. Department of Health and Social Security. H.M. Stationery Office, London.

Sutnick, A.I., London, W.T., Gerstley, B.J.S., Cronlund, M.M. \& BlumberG, B.S. (1968) Anicteric hepatitis associated with Australia antigen. Journal of the American Medical Association, 205, 670.

Szmuness, W., Prince, A.M., Goodman, M., Ehrich, C., Pick, R. \& AnSARI, M. (1974b) Hepatitis B immune serum globulin in prevention of nonparenterally-transmitted hepatitis B. New England Journal of Medicine, 290, 701.

Szmuness, W., Prince, A.M., Grady, G.F., Mann, M.M., Levine, R.W., Friedman, E.A., Jacobs, M.J., Josephson, A., Ribot, S., Shapiro, F.L., Stenzel, K.H., Suki, W.N. \& VYAS, G. (1974a) Hepatitis B infection: a point-prevalence study in 15 U.S. haemodialysis centers. Journal of the American Medical Association, 227, 901.

Villarejos, V.M., Visoná, K.A., Gutiérrez, A.D. \& Rodriquez, A.A. (1974) Role of saliva, urine and feces in the transmission of type B hepatitis. New England Journal of Medicine, 291, 1375 